D) This document has been downloaded from TamPub.uta.fi

The Insitutional Repository of University of Tampere

\title{
STABIUTY AND CHANGE IN THE STYLE AND STANDARDS OF EUROPEAN NEWSPAPERS' ARTS REVIEWS, 1960-2010
}

\section{Riie Heikkilä \& Jukka Gronow}

\begin{abstract}
Reviews of cultural products are central elements in creating, legitimizing and disseminating cultural tastes and hierarchies. In this empirical study, we examine the changes that have taken place in European newspaper reviews during the last fifty years (1960-2010). Our sample consists of 205 reviews found in Helsingin Sanomat (Finland), Le M onde (France), ABC/El País (Spain), Dagens Nyheter (Sweden) and The Guardian (UK). We close-read our sample using the framework of Shrum (1991) and observe changes in descriptive, entertainment, instructive, analytical, and evaluative schemes of the reviews. Unlike one might expect and contrary to the discourse of weakening, the changes between 1960 and 2010 are not drastic: if anything, the evaluation becomes more analytical and subtle.
\end{abstract}

Keywords: reviews, criticism, cultural gatekeepers, newspapers, cultural journalism, cultural sociology

\section{Introduction}

The act of reviewing cultural products provides an important structural framework for the symbolic production of culture and the arts (Janssen 1999, 1997; Shrum 1996, van Rees and Vermunt 1996). Reviews, as highly institutionalized and specialized texts, are "aesthetic selections by socially legitimated experts" (Janssen et al. 2011, 140). Reviewers can be considered important "tastemakers" and gatekeepers that allow only part of all cultural production to enter into the media by publicly stating its artistic value (Smith Maguire and M atthews 2014). In particular, when emphasizing the reviewer's gatekeeper role there are important power struggles embedded in the criticism of cultural products and artworks. In the process of evaluating such products, reviewers help to distinguish between the "pure" and "profane" culture (Bourdieu 1994, 1993); thus, the reviewer can be seen as a powerful player in the field of art. Critics are themselves part of the game, as just as there is no official education or title bestowed to become a reviewer, there is no objective way of authenticating the veracity or validity of their opinions (Van Rees 1989).

Highbrow arts such as opera, ballet, theatre and poetry have long been considered among the most prestigious sign of legitimate culture, and mastering or understanding them a sign of high levels of cultural capital in practically the entire Western world (Bourdieu 1984; DiM aggio 2012; Levine 1988). Newspaper reviews have been an essential part of these art forms almost from the beginning; reviewing can be seen as a way of connecting individual works of art with this wider field of cultural valuation, and of legitimizing and disseminating their symbolic valuations.

Reviewers are, of course, just one element of a much larger chain of cultural mediators at different levels. For instance, Janssen and Verboord (2015, 441-442) distinguish gatekeeping, co- 
creating (or editing), connecting/networking, selling/marketing, distributing, censoring/protecting/supporting and, finally, "evaluating, classifying and meaning making" from each other as different forms of mediating culture. According to this classification, reviewers do not only evaluate whether something is good or bad, or valuable or insignificant; they also have an essential role in creating and spreading hierarchies, exemplified well by the rise of jazz or cinema into the canon of high art (cf. Baumann 2007, or Janssen et al. 2011; see also Fishelov 2010). In the same vein, the criteria for reviewing are highly differentiated according to the genre in question (for an example of pop music reviewing and its audience-oriented criteria and style, see Van Venrooij and Schmutz 2010). Newspaper reviewing renews and strengthens power dynamics just like any other kind of criticism. For instance, debut novels are allocated less space in newspapers than novels written by established writers, and books published by large publishing houses get more coverage than those published by smaller companies (Janssen 1997; van Rees and Vermunt 1996).

In recent decades, reviewing practices have undergone substantial changes in terms of both the formats and the mediums in which their texts are published. While the circulation numbers of traditional outlets for reviews such as quality newspapers are decreasing everywhere in the Global North (cf. Brink Lund et al. 2011; Weibull and Nilsson 2010), the internet is becoming a substantial competitor to and replacement for traditional print media (M cChesney 2011). This change is reflected profoundly in reviewing. The era in which aesthetic-normative reviews were published mostly in print newspapers, catalogues or specialized magazines and written by authoritative experts, is over. There is now an increasing number of online reviews, published not only in electronic versions of traditional media but also in different web portals and personal blogs, bringing on the dimension of peer-produced review content and introducing profound changes in the valuations of the aesthetic criteria used in reviewing (cf. Verboord 2014). This recent fragmentation of traditional modes of criticism has led to many fears regarding the loss of traditional, authoritative and evaluation-based reviewing: "The critic-as-instructor, as objective judge and expert, has yielded to the critic who shares personal reactions and subjective enthusiasm. If anyone can be a critic, there is hardly any need for specialized and devoted professionals." (M cDonald 2007, 5). In the milieu of a transforming field of journalism, the act of reviewing conveys different, often converging and competing, roles, ranging from the traditional intellectual cultural critic to the everyday amateur expert (Kristensen and From 2015).

Newspaper reviewing has traditionally been considered to have a less legitimate aura than other types of reviewing or "serious criticism". According to Bourdieu, art reviews published in newspapers constitute a specific field between arts criticism and journalism (Bourdieu 1993); the cultural sections of newspapers have been called "soft journalism" to separate them from "harder" areas like politics or news (Kristensen and From 2012). In recent years, facing a crisis in circulation numbers, cultural sections have become increasingly interested in establishing links between the cultural product and the potentially interested consumer (cf. Verboord and Janssen 2015) - which has surely had an effect on reviewing practices. Following this argument, the journalistic reviewer has been considered a mere "consumer reporter [...] who records his or her likes or dislikes so that readers can use them to predict what shows, or books, or films they will like or dislike" (Carroll 2009, 8).

In the recent years, reviewing practices have raised the interest of several scholars as a way of exploring and tracking the legitimation of ideologies via the dissemination of specialist art and culture reviews (Baumann 2007; Janssen 1997; Johnston and Baumann 2007; van Venrooij and Schmutz 2010). How ever, to our knowledge, reviews have not yet been researched in light of the debate on the alleged crisis of cultural journalism and using longitudinal data derived from 
several different cultural domains. To do this, we use longitudinal newspaper data to assess the kinds of shifts that newspapers' reviewing practices have undergone during the last fifty years. Through a qualitative content analysis of a sample of reviews from five European countries, we focus on the possible shifts in five common elements of reviews. In the following chapters, we first discuss the context of newspaper reviewing and then analyze the changes to have taken place between 1960 and 2010, first by considering quantitative background information and then through the lens of our main sample of newspaper reviews gathered for the purposes of this study.

\section{Research design}

Using newspaper data drawn from different years solves the common problem encountered in cultural sociology: the scarcity of suitable longitudinal data. Our full data set derives from a larger cross-national, longitudinal research project on the relationship between cultural and social stratification in post-1960s Europe (cf. Author 2015). The following newspapers and countries were included in this study: Helsingin Sanomat (HS) from Finland, Dagens Nyheter (DN) from Sweden, The Guardian (GU) from the UK, Le M onde (LM) from France, and ABC/El País (ABC/EP) ${ }^{1}$ from Spain. The chosen newspapers share similar political views (with the exception of $A B C$ ), they all have roughly comparable circulation numbers, and they can be considered nationally important quality dailies (cf. Author 2017; Janssen et al. 2008; Jaakkola 2015; Verboord et al. 2015). Culture and arts sections were created in most major European newspapers around the middle of the 20th century (Jaakkola 2015), which makes 1960 an interesting starting point for the exploration: using ten-year intervals between 1960 and 2010, we collected altogether 11,775 articles on culture from the newspapers from six time points (1960, 1970, 1980, 1990, 2000 and 2010). In order to eliminate seasonal variation in arts coverage, we used "constructed weeks" (Riffe et al. 1993; Janssen et al. 2008): each time point was divided into thirds for which one full week was randomly constructed, totalling three weeks per selected year. We avoided the problem of operationalization by including all articles published in the chosen cultural sections and thematic cultural supplements. The articles were coded using Atlas.ti and a code system of 49 variables. Standard inter-coder reliability tests were conducted (Krippendorff 2004), with satisfactory results (Author 2015). The coding process and some of the variables and their categories were designed according to the work of Janssen et al. (2011) to allow for future comparisons.

We pursued answers to our research questions from both quantitative and qualitative angles. For the purposes of this paper, and to provide a background quantitative analysis, we extracted all the reviews $(n=3,770)$ from the full data set $(n=11,775)$ and analyzed them using three variables: the type of article, coded into 1) review/critique, 2) interview/profile, 3 ) commentary text, 4) report/feature, 5) news, 6) preview, 7) announcement/list, 8) artistic text/fiction and 9) other); the size of the article, coded into 1) multiple pages, 2) whole page, 3) half of the page, 4) quarter page, 5) smaller article and 6) very small article); and finally the cultural field of the review, originally coded into 21 categories and further recoded into the most commonly review ed cultural domains: 1) novels, 2) all other literature, 3) pop music, 4) classical music, 5) film, 6) TV, 7) theatre, 8) fine arts and 9) other (including everything else).

In addition, we constituted a smaller subsample of the full data consisting of theatre, novel $^{2}$ and classical music reviews from the years 1960, 1980 and 2010. For each of these years, we selected five reviews per cultural domain and per country, thus altogether 225 reviews. There were some lacks of suitable reviews that meant our sample did not reach that number: $A B C$ published no novel reviews in 1960, GU published no novel reviews in 1980, EP published only two 
theatre reviews in 2010, ABC published only one classical music review in 1960 and LM published only four classical music reviews in 1960 and three in 2010. Thus, the final sample consisted of 205 reviews. While recognizing that the three chosen cultural domains include a variety of subgenres and types of cultural production, and vary across time, we argue that they form a data set homogeneous enough to be studied as an example of highbrow reviews published in European quality newspapers. Theatre, novel and classical music reviews were chosen for several reasons. First, we wanted to include only internationally common cultural domains with long-standing historical roots; second, we wanted only areas considered 'highbrow' (see for instance Janssen et al. 2011) in order to make our sample as homogeneous as possible in terms of style; third, we wanted to include differently distributed cultural domains: one based on performing or live arts, (theatre) one functioning merely through different distributable and portable 'recordings' or reproductions (novels) and one distributable in both ways (classical music). Whenever not written originally in English (like in the case of reviews in GU), the review excerpts used were translated by the authors into English.

We addressed our subsample using qualitative content analysis. Adapting the model of Schreier (2012), we first decided on our research question, then selected our material, decided on a suitable coding frame, divided our material into units of coding (individual articles derived from different years and cultural fields), tested and modified the coding frame and finally close-read the subsample while making formative and finally summative checks on reliability. During the close reading, we also looked for suitable examples of each of our coding categories (see next section) and made comparisons across different years and cultural fields. Lastly, we interpreted our results in light of the original research question.

In the literature, the most classical and common tasks assigned to reviewers are undoubtedly describing, interpreting and evaluating (van Rees and Vermunt 1996). Wishing to enlarge our scope of analysis and make it apt for analyzing changes in highbrow reviews, our coding frame was inspired by Shrum's (1991, 352): he distinguishes five components of reviews that could also be seen as "performance objectives" of the reviewer. Descriptive elements refer to basic information about the cultural product (performers, authors, setting etc.). Analytical elements provide the interpretative context for understanding the cultural product at hand (metaphors, symbolic meanings in the work etc.). Entertainment elements include humor, wit, displays of outrage and other verbal resources used by the reviewer. The instruction element refers to indirect or straightforward advice to the artist(s): mainly explicit tips on how to make the cultural product better. The evaluative element, the possible weakening of which we assumed might work as a proxy for the possible 'crisis' in reviewing, is in many ways the backbone of what reviews stand for, namely positive or negative judgements about the artwork and recommendations for the potential consumer. Thus, these categories formed the basis of our qualitative content analysis.

\section{Results}

Figure 1 shows the relative shares of different article types in our data drawn from European newspapers in different years. We can see that reviews are by far the most common type of articles found in our full data. Figure 1 also demonstrates that the relative amount of reviews has grown notably between 1960 and 2010; in 2010, four out of ten articles are reviews, and all other types of article are far behind that numerically. The relative share of reviews rose remarkably from 1960 to 1980, and after a slight decline in 1990 and 2000 reached a new record in 2010. At the 
same time, the share of pure news has declined greatly since 1980, from one quarter of all items to around one in seven. Criticism seems to have preserved - or even strengthened - its position in quality newspapers.

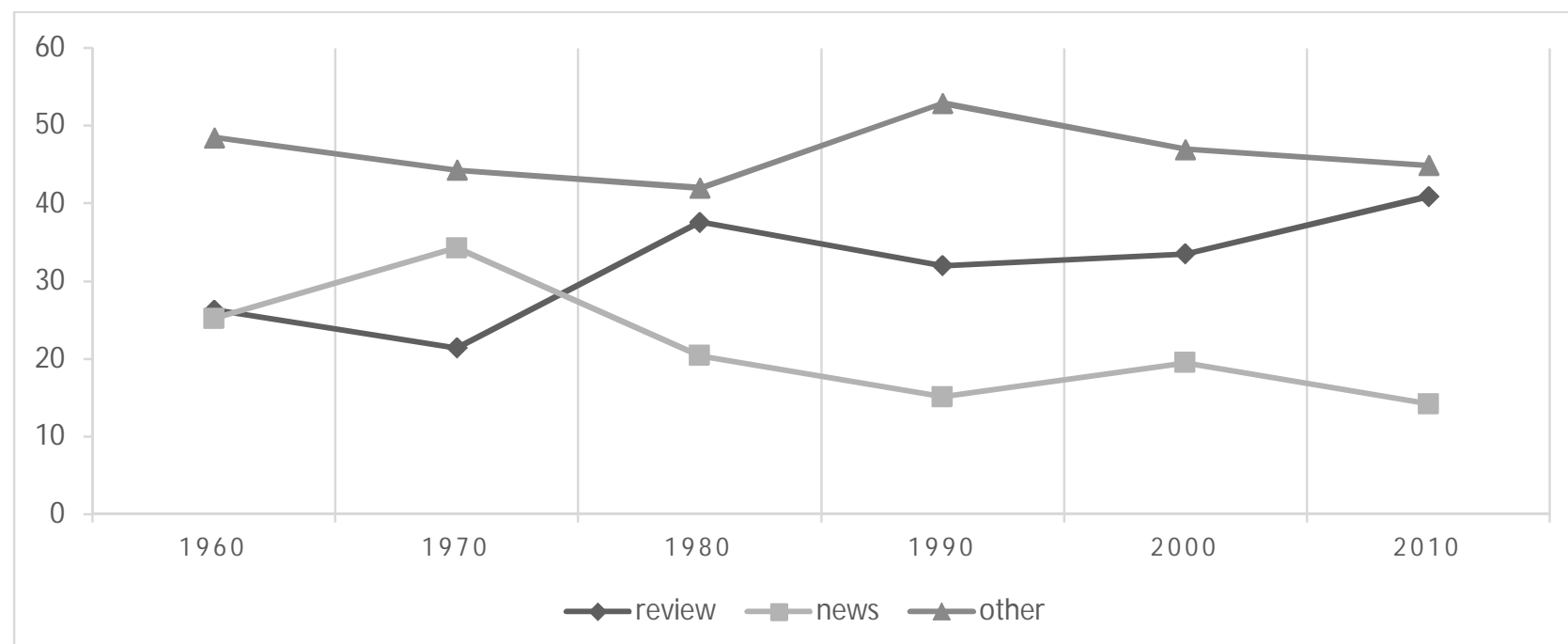

Figure 1: Type of article per year, percentages. $(N=11,658)$

Figure 2 reveals that the size of the reviews echoes the findings on the frequency of reviews in newspapers; the relative amount of very long reviews is larger in 2010 compared to all other years. The relative amount of half-page reviews increased since 1970 only to decline again after 1990. The increase in the share of quarter-page reviews has faced a similar trajectory, but the decline started in 2000 in this case. However, both have remained at a level higher than their starting points in 1960.

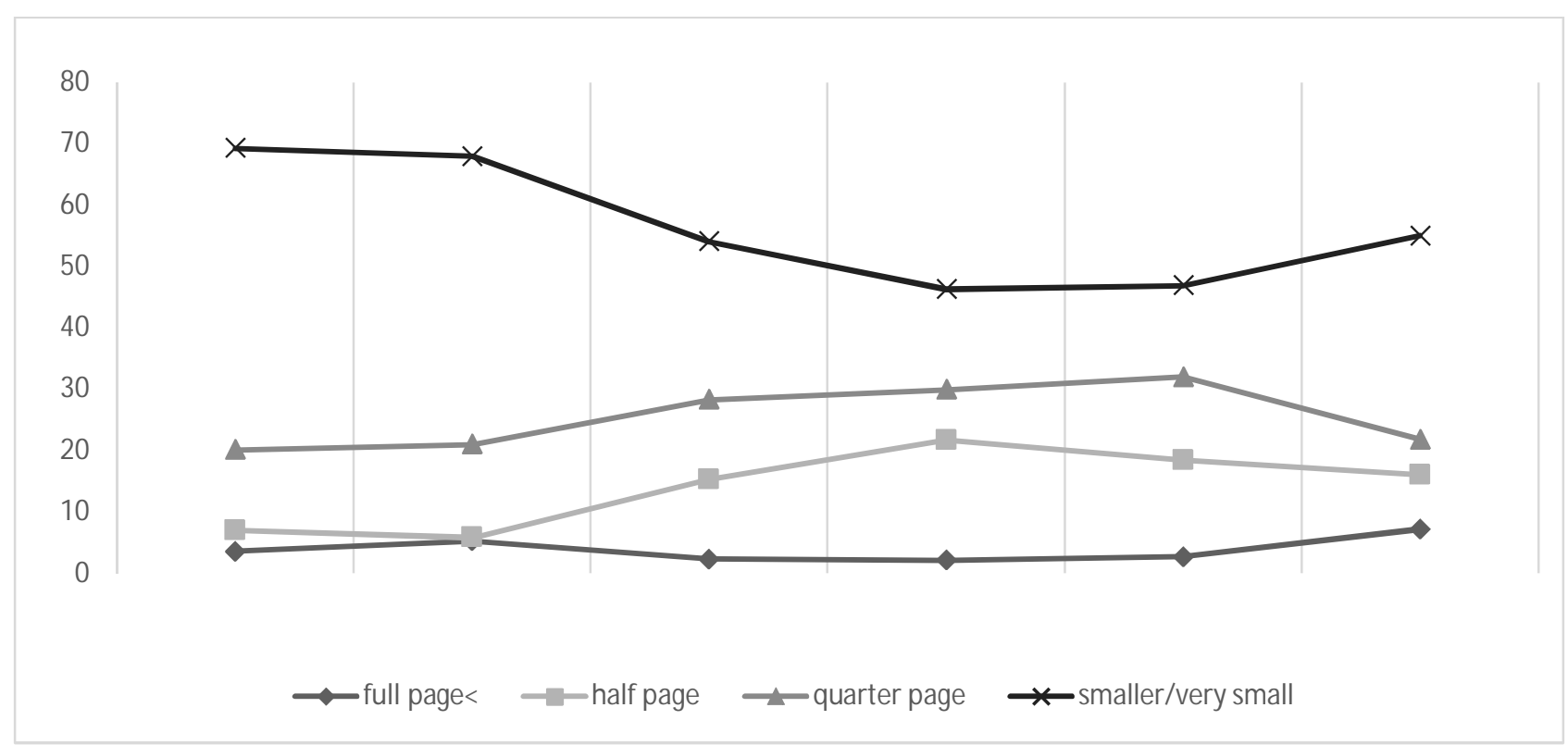

Figure 2: Size of the reviews per year, percentages. $(N=3,767)$

Table 1 shows the distribution of different cultural domains in all reviews $(n=3,778)$. We can see that the absolute amount of reviews grows notably overall (with some decrease between 2000 and 2010), which means there is some level of increase in almost all of the cultural domains. Pop 
music reviews grow spectacularly in both absolute and relative numbers (while classical music reviews decrease in relative but not in absolute numbers). The relative amounts of novels, film and fine arts reviews are roughly similar across years. The most dramatic decrease is in theatre reviews, which diminish from almost 20\% to only 7\% between 1960 and 2010; it is the only cultural domain that decreases in terms of both relative and absolute numbers.

Table 1. Frequencies and distributions of different cultural domains across time $(\mathrm{N}=3,778)$.

\begin{tabular}{|c|c|c|c|c|c|c|c|}
\hline & 1960 & 1970 & 1980 & 1990 & 2000 & 2010 & Total $(\mathrm{N})$ \\
\hline \multirow[t]{2}{*}{ Novels } & 39 & 16 & 41 & 59 & 93 & 113 & 361 \\
\hline & $10,9 \%$ & $4,0 \%$ & $7,9 \%$ & $9,0 \%$ & $10.0 \%$ & $12,5 \%$ & $9.6 \%$ \\
\hline \multirow[t]{2}{*}{ Other literature } & 49 & 60 & 109 & 121 & 200 & 187 & 726 \\
\hline & $17.3 \%$ & $15.2 \%$ & $21,7 \%$ & $20,6 \%$ & $21,8 \%$ & $20,7 \%$ & $20,3 \%$ \\
\hline \multirow[t]{2}{*}{ Pop music } & 13 & 18 & 76 & 103 & 179 & 214 & 603 \\
\hline & $3.6 \%$ & $4,4 \%$ & $14,8 \%$ & $15,7 \%$ & $19.9 \%$ & $23,9 \%$ & $16 \%$ \\
\hline \multirow[t]{2}{*}{ Classical music } & 57 & 80 & 80 & 103 & 94 & 100 & 514 \\
\hline & $15.6 \%$ & $19.7 \%$ & $15.6 \%$ & $15.7 \%$ & $10.0 \%$ & $11.1 \%$ & $13.6 \%$ \\
\hline \multirow[t]{2}{*}{ Film } & 38 & 58 & 46 & 47 & 104 & 97 & 390 \\
\hline & $10.4 \%$ & $14,3 \%$ & $9.0 \%$ & $7,2 \%$ & $11,0 \%$ & $10,8 \%$ & $10.3 \%$ \\
\hline \multirow[t]{2}{*}{ TV } & 21 & 21 & 16 & 26 & 33 & 24 & 141 \\
\hline & $5,8 \%$ & $5,2 \%$ & $3,1 \%$ & $4,0 \%$ & $3.5 \%$ & $2,7 \%$ & $3.7 \%$ \\
\hline \multirow[t]{2}{*}{ Theatre } & 69 & 79 & 54 & 51 & 48 & 64 & 365 \\
\hline & $18,9 \%$ & $19.5 \%$ & $10,5 \%$ & $7,8 \%$ & $5,1 \%$ & $7,1 \%$ & $9.7 \%$ \\
\hline \multirow[t]{2}{*}{ Fine arts } & 22 & 26 & 43 & 46 & 60 & 40 & 237 \\
\hline & $6,0 \%$ & $6,4 \%$ & $8,4 \%$ & $7,0 \%$ & $6,4 \%$ & $4,5 \%$ & $6,3 \%$ \\
\hline \multirow[t]{2}{*}{ Other } & 42 & 46 & 46 & 85 & 116 & 60 & 395 \\
\hline & $11.5 \%$ & $11.3 \%$ & $9.0 \%$ & $13.0 \%$ & $12,3 \%$ & $6.7 \%$ & $10.5 \%$ \\
\hline \multirow[t]{2}{*}{ TOTAL } & 365 & 406 & 513 & 654 & 943 & 897 & 3778 \\
\hline & $100,0 \%$ & $100,0 \%$ & $100,0 \%$ & $100,0 \%$ & $100,0 \%$ & $100,0 \%$ & $100,0 \%$ \\
\hline
\end{tabular}

We have seen so far that newspaper reviews have been relatively successful in terms of keeping up as a journalistic genre and the space allotted to them in quality newspapers. While the relative and absolute numbers of reviews have grown, the growth is not distributed equally across cultural domains. We shall next scrutinize the changes that have taken place in the content and style of reviews through a qualitative reading of our sample, using Shrum's (1991) categorization of analytical components that are essential to all reviews.

Descriptive elements include information about the cultural product in question, the possible performers, the setting and so on. The descriptive element is essential in providing the necessary practical information on how to access the cultural product in question, "to serve as a kind of thumbnail synopsis of what the audience may expect" (Shrum 1991, 352). According to our reading, the descriptive element is undoubtedly the most common and lasting element of European newspaper reviews. Therefore, description can be seen as constituting the most basic element of any review. The format has remained largely intact but has undergone some changes, from detailed in-text presentations in 1960 to visually simple and appealing text boxes from 1980 onwards. Both formats, in any case, contain the same kind of description of the events: time, location, artists, and in the case of 2010, often the price of the cultural product, whether it is a live show or a cultural item for personal consumption.

His puppets help him because they really know the music, for instance Lucien Nat and Dora Doll, or because they are cute, like Jaqueline Joubert. There is also Philippe Lemaire. If you like this, you should know that at 9 PM, rue Daunou, you will burst into unexpected laughter five or six times. This is it. LM 1960

The year of Richard ("L'année de Richard"), text and direction: Angélica Liddell. With Angélica Liddell and Gumersindo Puche. Chapelle des Penitents-Blancs, 10 PM. Tel. 04-90- 
14-14-14. From 13 to 27 euros. From 7 PM to 10 PM. Duration: 2 hours. Spanish subtitles. LM 2010

In turn, entertainment elements (humour, wit and displays of erudition or outrage) are present throughout the studied period, but their manifestations vary; in 1960, they are mainly displays of indignation and outrage, replaced by subtler humour and wit in later years. In the 1960s, the entertainment elements are typically rather simple displays of outrage or erudition.

\section{This is not a play it is a massacre. GU 1960}

The city of Coventry, guided by the broad pen of John Wyles, indulges in a hot bash of masochism in this play, and the emphasis is on broad and bash. It is a theatrical occasion when to watch the audience is more instructive than to watch the stage. The boxes wince. The stalls glance uneasily over shoulders. The circle is in a flat spin. Through it all the theatre rocks with "I'm all right, Jack" laughter. GU 1960

Later, more clearly in 2010 than in 1980, the reviews become more humorous in style and dispose of a wider array of expressing feelings. The general style of the reviews becomes looser and more freely formulated through time, and in $\mathbf{2 0 1 0}$ many reviews clearly have entertainment elements:

Something in the book obviously appeals to the reader since even a more prejudiced reader has the strength to read it all through. It works as an entertainment and one cannot but admire the author of this book, which is thick as a brick. There is hardly a dead page anywhere. HS 2010

The dialogue he produces is a strange hybrid that has one foot in Dumas and the other in the Channel 4 drama about sozzled teenagers: stately exchanges come punctuated with racy colloquialisms such as "completely mental" or "feeling a bit wooh". GU $\mathbf{2 0 1 0}$

Instruction elements in the form of statements prescribing styles, emphasis or alternatives for cultural producers are, according to Shrum (1991, 352), relatively rare and more often implicit in evaluation. However, our analysis shows that instruction abounds. It is rather straightforward in 1960 - most reviews show it explicitly - but since 1980, the instructive element has become more subtle in tone. From a contemporary point of view, the instructive element used in the 1960s reviews is rather pitiless, and often focuses on the artists personally:

One is tempted to tell Sylvie Favre that her ability to play the lost boys found was worthier of her skills in Barrage contre le Pacifique, and to Suzanne Flon that her immense talent fits better the texts of Anouilh or Audiberti. LM 1960

Her dialogue is a mixture of quasi-music-hall (a sort of poor man's Osborne) and idiomatic pointlessness. At its best it has the virility of vulgarity, at its worst it stinks of self-

indulgence. (...) M iss Delaney has a sharp eye and a talent (..) but one of these fine days she is going to have to sit down and learn to construct a play, and to ponder on the evidence of dramatic history that there is such a thing as Art, and that sight without imagination and words without meaning are a dead, dead loss. GU 1960 
While in the 1960s the instruction element is explicit, it does not disappear totally entirely over time. It does become subtler, more conditional and without doubt much less sarcastic and more focused on the personal experience of the reviewer:

By heavily cutting the text, this could be quite a decent twenty-minute presentation. HS 1980

A bigger font and some illustration more than only Lotta Kauppi's vignettes would have made it easier to internalize the bumpy ride. HS $\mathbf{2 0 1 0}$

I could have done with more fire from Tam Williams as the younger Absolute, and Hall's production can't rival Peter Wood's 1983 National Theatre revival in its social detail. GU 2010

Analytical elements provide a context for and an interpretation of the cultural product at hand; this can be achieved through, for instance, metaphors, symbolic meanings or open questions. According to Shrum $(1991,352)$, it is a reflection of "the critics' own proposals for the constructions of aesthetic significance". The analytical side may contain elements from a wide range of contexts (for instance, historical, linguistic or political frames). In some specific national and historical cases the analytical element overpowers all other elements. A good example is Spanish newspaper EP in 1980, in which almost all analyzed reviews of novels focus on the difficult political situation of the time. One could also add that a review often places its object within a specific genre - or alternatively contrasts it with some well-known genres - thus making it more familiar to the reader and its interpretation easier.

Contrary to what could have been expected in light of the discussion on the crisis of cultural journalism, the analyzed reviews have, in fact, become more reflective and analytic through the years. This development is especially noticeable between 1960 and 1980; after that there is less change. In longer reviews, there is typically always an analytic element disregarding the year and the context.

Pohjanpää (the author) says what he has to say with simple, polished and plain means... one cannot avoid a certain anomic feeling that even as such the tone is personal, sincere as a child's... HS 1960

The scratched sforzendo chords, the quick and slow crescendos and diminuendos, even the occasional dynamically level single note, that Gerhard has written for it here, all immediately catch the ear as new and fascinating sounds. GU $\mathbf{1 9 8 0}$

The atmosphere of the novel is, in a way, derived from the famous Poem 'A une Passante' in which instanity was born through eternity for the modern man. Jean Bosman is, also in a way, a flaneur himself, or better put, something that has converted into a flaneur of the modern times. Nervousness, loss, confusion, anxiety... the feelings are different, but we recognize the figure. EP 2010

Rather often, the analytical element introduces open questions and possible modes of interpretation to the reader, rather than offering ready-made significations: 
Is Querry a Graham Greene that explains, in the very end, that he cannot continue taking seriously this game of damnation and redemption? Or is Querry a Graham Greene that moves all the way to redemption, to the other side of the grave? DN 1960

Is this a highlight of psychological literary art? Can you imagine at all how she was feeling? I only find the floundering lists comical and find myself being curious about what kind of supernatural things she tries to evoke. DN 1980

A lasting, non-changing and rather banal means of analytical contextualization is referring to other artists and artworks. Examples are plentiful, and they abound in all decades and within all the cultural domains studied:

Passion is for them like the context that brought us Tristan and Isolde, Paola and Francesca. LM 1960

It is possible that you have to go all the way to Per Gunnar Evander to find an author that depicts Swedish loneliness with the same absolute empathy. [...] I personally cannot watch "Den gråtande polisen" without thinking of Lars Andersson's novel "Snöljus". DN 1980

M üller's bright and flinty language condenses time after time into a poem: in Auberg's expressions referring to escaping, eating and being hungry, Hengityskeinu [the novel] is related to Paul Celan, a survivor of the Holocaust, who looked for a clean field of meanings beyond normal language. HS $\mathbf{2 0 1 0}$

\section{A Nordic Schumann for whoever wants to listen to it. GU $\mathbf{2 0 1 0}$}

The evaluative element is the fifth element analyzed in our study. It is quite naturally an essential element of cultural criticism; without it, reviews would resemble more cultural news than critical assessments. In line with the other elements scrutinized, the evaluative element has developed from black-and-white and harsh to become more careful, sensitive and dialogic. One can also identify a gradual change from the evaluation of details to an evaluation of the totality.

In the 1960s, the evaluative element is usually expressed in such a dramatic way that the aesthetical quality of the cultural product seems undisputed. The focus of the evaluation is typically on details like specific movements or characteristics.

So many mistakes all at the same time! [...] The show would have benefited from lasting even less, as the rare few silent moments of Phaedra clopping around or making sudden pirouettes is close to buffoonery. LM 1960

Asfar as I know, this was the first time Göta Blomberg sang the alto roles. Her beautiful voice and cultured manner of performing were attractive even if it seemed like the singer was not in her best condition. DN 1960

Towards the 1980s, the evaluation evident in the reviews develops towards a much more diplomatic and subtle approach. Reservations about the rank of the cultural product are expressed as doubts, questions and limitations, rather than through reproaches or comments on possible mistakes. 
Perhaps the staging of Jacques Lassalle and the acting both lack a minimal necessary dose of humour? Perhaps, since the only breath, the only light of the evening, is accredited to the presence of actor Jean Dautremay. LM $\mathbf{1 9 8 0}$

It is a beautiful circus of a production and Roger Rees as Semyon and a fine cast functions very well within the limitations of this scene. GU $\mathbf{1 9 8 0}$

At the content level, evaluation focuses less on details over the years. In the 1960s and 1980s, the reviews still pay a great deal of attention to the specific minutiae of the cultural products; key elements like artists are often mentioned by name, and distinct elements of the artwork are evaluated separately.

The choir, led with delicacy, mastery and sensitivity by José Perera, was finely in tune and showed an excellent quality in tone and brilliance. Only some episodic unsteadiness of the womens' high voices and a palpable coarseness in the male voices limited perfection. ABC 1960

She has a nice voice, which modulates and alters convenience; a fair gesture, a very expressive face. She is not always correct in the interpretation of texts. EP 1980

Chris Hunter also offers a formidable autumn treble as a mutinous baby, the Witch's hat and a piggy servant whose heart is at one point noisily removed. The play itself is a daunting celebral frolic that left me hungering for Humperdinck and yearning for Grimm.

\section{GU 1980}

In contemporary times, reviews focus far more on the aesthetic value of the totality of the cultural product in question. Individual actors are still mentioned often, but their separate roles are no longer specified.

The team of actors (Nao Albet, M arcel Borras, Clara Cols, Biel Duran, Jordi Figueras, Lina Lambert, Agnes M ateus and Juan Navarro) is formidable, but after enjoying a meal of four dishes I leave the theatre feeling hungry, with voice and teeth and ears of Bugs Bunny: This is it, folks? Is this story everything this hotbed of stories offers - history? Any TV show of Jaime de Armiñán did triple in the same time: quick, accurate portraits of a time, a country, of people. EP 2010

Abstract and impersonal, the prose fairly gleams in these pages: this is the modern city as a form of distractedness, its self-ironising characters perpetually in a "state of becoming". GU 2010

Albeit not the main topic of this paper, it is notew orthy that the analyzed elements of reviews from different cultural domains face the changes in somewhat distinct ways. We have already mentioned that contemporary reviews have a general tendency of evaluating totality rather than details. This materializes differently in different cultural domains. In the theatre reviews of the 1960s, most reviews mention the reactions of the audience, such as the applause or noisy discontent of the public. For instance, a theatre review published in ABC in 1960 notes: 
Salvador Ferrer M aura came to greet (the public) at the end of the representation together with director Suarez Radillo and the actors amongst the applause of the audience, who cheered at the end of the first half and who laughed in some situations and with certain comic lines of the play.

In 2010, attention is focused on the totality and on the experience of the spectator (or reviewer); the audience as an entity is rarely mentioned. In the novel reviews of the 1960s, much attention is paid to the plot, but in more contemporary times, the attention turns to the author, sometimes to the extent that the reviews focus more on them than the novels under consideration. For instance, one of the first sentences of the El País review of Barbara Pym's novels Jane and Prudence and A Glass of Blessings (in Spanish Los hombres de Wilmet) starts by stating that "Barbara Pym (1913-1980), a contemporary of M uriel Spark, Jean Rhys or Iris M urdoch, is one of the smartest writers contemporary English fiction has given us", and it is not until the fourth paragraph of the six in total that the reviewer starts to write about the novels in question. We interpret these shifts as part of a general turn towards human-interest themes in cultural journalism (Kristensen and From 2012), and as a possible relocation of attention from the artwork to its creator(s). Interestingly, the reviews of classical music differ from the other reviews analyzed here in this respect. First, they have remained more similar over time than other reviews in terms of style and evaluation criteria. Second, they are often more technical and use specific musical terminology (allegro, vivace etc.) which is taken as granted as common knowledge. Literary and theatre reviews make do without invoking such specialized knowledge. We could conclude that among the cultural domains under examination, reviews of classical music are openly elitist and best conserve the ideals of traditional, authority-based reviewing.

\section{Conclusion and discussion}

If judged based on our quantitative inquiry, we have seen that newspaper reviews are a growing genre of cultural commentary, as both their numbers and relative size have increased during the period under study. Newspaper reviews have taken on new features during this period; their layout has changed and become much more attractive for the reader, which in deed characterizes the development of newspaper layouts in general. (cf. Author 2017.) The cultural pages in general are increasingly more attractive for the consumer (cf. Janssen and Verboord 2015) and attuned to the growing competition for potential readers' interests. For instance, we showed that in contemporary newspapers, essential information about the cultural products (name, name of artist, price and so forth) is often presented in separate text boxes and not scattered in the evaluation or omitted totally as was the case fifty years earlier. To recap, we did not find any signs of a decline of cultural reviews in the studied leading newspapers in our five countries. If anything, the reviews have become more analytical and reflective, and the reviewers now show their expertise more clearly. The major changes, if any, occurred rather early in our period of study, between 1960 and 1980.

Between 1960 and 2010, there was a clear move towards delivering a more personal tone that emphasized the experience of the critic. This reflects the findings of several other scholars on the relativisation and subjectivisation of contemporary journalism (Hellman and Jaakkola 2012; Jaakkola et al. 2015; Kristensen 2010); journalism in general is seen to have become increasingly focused on storytelling, than on adhering to traditional journalistic values like keeping a critical distance and avoiding personal opinions: "The personification and eventification of cultural 
journalism have brought it closer to liquid modern general journalism, with journalists producing content where emotional appeal, storytelling, debate and entertainment are emphasized"(Jaakkola et al. 2015, 819). This tendency is clear in reviews, but it does not mean their intrinsic characteristics - most importantly evaluation - have suffered.

In general, we have found that the changes in the reviews are not very systematic or remarkable, and that the reviews have in fact preserved many of their essential features intact up till 2010. Cultural evaluations have become more subtle and reflective, and when there is judgement, it is not presented in such harsh and straightforward terms as in 1960. The humor and wit used in the reviews has also become much more delicate and finessed. The style of writing and the format of contemporary reviews are less strict and more varied in style than fifty years ago. This is accompanied by, and perhaps is also a consequence of, the fact that the evaluations pay more attention to the totality of the work instead of (and in some cases, in addition to) its details and individual components. The table below summarizes some of our basic findings in these respects.

\begin{tabular}{|l|l|}
\hline Starting point, $\mathbf{1 9 6 0}$ & Shifts towards $\mathbf{2 0 1 0}$ \\
\hline News-oriented, small reviews & Large, comprehensive reviews \\
\hline $\begin{array}{l}\text { The (reaction of the) public / the reader as } \\
\text { a measure of aesthetic value }\end{array}$ & $\begin{array}{l}\text { The (personal) experience of the critic as } \\
\text { a measure of aesthetic value }\end{array}$ \\
\hline Black-and-white evaluation & $\begin{array}{l}\text { Dialogic (sometimes more careful) } \\
\text { evaluation }\end{array}$ \\
\hline Tight formalities (and textual traditions) & Highly differentiated styles of writing \\
\hline $\begin{array}{l}\text { Focus on the details of the artwork (plot, } \\
\text { actors, setting) }\end{array}$ & $\begin{array}{l}\text { Focus on not only the details, but also the } \\
\text { totality of the artwork }\end{array}$ \\
\hline NOVELS: importance of the plot & $\begin{array}{l}\text { NOVELS: increasing importance of the } \\
\text { author }\end{array}$ \\
\hline THEATRE: importance of the audience & $\begin{array}{l}\text { THEATRE: increasing importance of the } \\
\text { totality }\end{array}$ \\
\hline $\begin{array}{l}\text { MUSIC: less accentuated change as in the } \\
\text { case of other genres; a general elitist tone }\end{array}$ & \multicolumn{2}{|l}{} \\
\hline Tight layout, few pictures & Aird layout, more pictures \\
\hline
\end{tabular}

Table 2. Overall changes taken place in the reviews between 1960 and 2010.

To conclude, our research has touched upon the changes that have taken place in the reviews of a highly specific kind of institutionalized media: newspapers. Our sample was derived from six wellrespected European quality dailies. While embedded in different media system models (cf. Hallin and M ancini 2004), the newspapers were rather similar in style, and there were no noticeable differences between the reviews extracted from them. This is perhaps attributable to the newspaper institutions themselves; traditional quality newspapers in their printed format, like the ones we have studied here, can easily be considered a rather conservative, slowly changing structure, which does not necessarily reflect well the rapid changes that have taken place in the field of culture. We consciously concentrated only on highbrow reviews in order to make our sample as homogeneous as possible; extending the qualitative exploration to reviews of cultural domains considered emerging or popular, such as film and popular music, is a task for future research.

We detected no trends indicating drastic changes, not that spoke to a 'crisis', in the longstanding elements of newspaper reviews of traditional highbrow arts between 1960 and 2010 . Nevertheless, several ongoing structural changes will probably bring changes in future newspaper reviewing. Declining newspaper readership, the extension of reviewing in the digital media, forms of publishing not dependent on gatekeepers, the proliferation of peer-produced criticism and the 
general de-hierarchization in terms of the reviewer's expertise are phenomena that have prompted important discussions in recent years (Brink Lund et al. 2011; Kristensen and From 2015; Verboord 2014; Verboord 2014; Weiss Hanrahan 2013) and that clearly deserve more attention. The changes in traditional quality newspapers in the latter half of the 20th century, as we have studied in this paper, perhaps provide us a glimpse of what is ahead.

\section{NOTES}

1. We use two different Spanish newspapers for historical reasons. El País is the logical equivalent for the other newspapers, but it was founded only in 1976 after the Spanish transition to democracy so we were able to include it our data only from 1980 onwards. For the remaining years (1960 and 1970), we chose ABC, a right-wing yet liberal publication, with large circulation numbers.

2. The original coding system had altogether 9 variables for literature. These were: poetry, novel, whodunnit/thriller, other fiction, non-fiction: philosophy/religion, non-fiction: science/nature, nonfiction: history, other non-fiction and autobiography. For our subsample, we only chose "novels", thus omitting for instance thrillers.

\section{REFERENCES}

Arora, Payal, and Filip Vermeylen. 2013. "The end of the art connoisseur? Experts and knowledge production in the visual arts in the digital age." Information, Communication \& Society 16 (2): 194214.

Carroll, Noël. 2009. On Criticism. New York: Routledge.

M cChesney, Robert W. 2011. "The crisis of journalism and the Internet." In News Online:

Transformations and Continuities, edited by Grahan M eikle, and Guy Redden, 53-68. London: Palgrave Macmillan.

Elkins, James. 2003. What Happened to Art Criticism? Chicago: Prickly Paradigm Press.

Baumann, Shyon. 2007. "A general theory of artistic legitimation: How art worlds are like social movements." Poetics 35 (1): 47-65.

Bourdieu, Pierre. 1993. The Field of Cultural Production. New York: Columbia University Press.

Bourdieu, Pierre. 1994. "L'emprise du journalisme." Actes de la Recherche en Sciences Sociales 101 (1): 3-9.

Brink Lund, Anker, Karin Raeymaeckers, and Josef Trappel. 2011. "Newspapers: Adapting and experimenting." In M edia in Europe Today, edited by Josef Trappel, Werner A. Meier, Leen D'Haenens, Jeanette Steemers, and Barbara Thomass, 45-59. Bristol: Intellect. 
DiM aggio, Paul. 2012. "Sociological perspectives on the face-to-face enactment of class distinction." In Facing Social Class, edited by Susan Fiske, and Hazel Rose Markus, 15-38. New York: Russell Sage Foundation.

Fishelov, David. 2010. Dialogues with/and Great Books. Brighton, PA: Sussex Academic Press.

Hallin, Daniel C., and Paolo M ancini. 2004. Comparing M edia Systems. Cambridge: Cambridge University Press.

Hanrahan, Nancy W. 2013. "If the people like it, it must be good: Criticism, Democracy and the Culture of Consensus." Cultural Sociology 7 (1): 73-85.

Heikkilä, Riie, Tina Lauronen, and Semi Purhonen. 2017. "The Crisis of Cultural Journalism Revisited: The Space and Place of Culture in Quality European Newspapers from 1960 to 2010." European Journal of Cultural Studies. DOI: 10.1177/1367549416682970 (OnlineFirst 4 January 2017).

Hellman, Heikki, and Maarit Jaakkola. 2012. "From aesthetes to reporters: The paradigm shift in arts journalism in Finland." Journalism: Theory, Practice and Criticism 13 (6): 783-801.

Jaakkola, Maarit. 2015. The Contested Autonomy of Arts and Journalism: Change and Continuity in the Dual Professionalism of Cultural Journalism. Tampere: Tampere University Press.

Jaakkola, Maarit. 2015. Outsourcing views, developing news. Changes in art criticism in Finnish dailies, 1978-2008.

Jaakkola, Maarit. 2014. "Witnesses of a cultural crisis: Representations of media-related metaprocesses as professional metacriticism of arts and cultural journalism." International Journal of Cultural Studies 18 (5): 537-554

Jaakkola, Maarit, Heikki Hellman, Kari Koljonen, and Jari Väliverronen. 2015. Liquid M odern Journalism with a Difference. The changing professional ethos of cultural journalism. Journalism Practice 9 (6): 811-828

Janssen, Susanne. 1997. “Reviewing as social practice: Institutional constraints on critics' attention for contemporary fiction." Poetics 24 (5): 275-297.

Janssen, Susanne. 1999. "Art journalism and cultural change: The coverage of the arts in Dutch newspapers 1965-1990." Poetics 26 (5/6): 329-348.

Janssen, Susanne, Giselinde Kuipers, and M arc Verboord. 2008. "Cultural globalization and arts journalism: The international orientation of arts and culture coverage in Dutch, French, German, and the U.S. newspapers, 1955 to 2005. " American Sociological Review 73: 719-740.

Janssen, Susanne, and M arc Verboord. 2015. "Cultural mediators and gatekeepers. " In International Encyclopedia of the Social \& Behavioral Sciences, edited by James D. Wright, 440446. Amsterdam: Elsevier. 
Janssen, Susanne, Marc Verboord, and Giselinde Kuipers. 2011. "Comparing cultural classification. High and Popular Arts in European and U.S. Elite Newspapers, 1955-2005. " Kölner Zeitschrift für Soziologie und Sozialpsychologie 63 (51): 139-168.

Johnston, Josée, and Shyon Baumann. 2007. Democracy versus Distinction: A Study of Omnivorousness in Gourmet Food Writing. American Journal of Sociology 113 (1). 165-204.

Krippendorff, Klaus. 2004. Content Analysis: An Introduction to its M ethodology (2nd Edition). Thousand Oaks, CA: Sage.

Kristensen, Nete Nørgaard. 2010. "The Historical Transformation of Cultural Journalism." Northern Lights 8 (1): 69-92.

Kristensen, Nete Nørgaard, and Unni From. 2015. "From Ivory Tower to Cross-M edia Personas: The heterogeneous Cultural Critic in the M edia." Journalism Practice 9 (6): 853-871.

Kristensen, Nete Nørgaard, and Unni From. 2012. "Lifestyle journalism: Blurring boundaries." Journalism Practice 6(1): 26-41.

Levine, Lawrence W. 1988. Highbrow/Lowbrow: The Emergency of Cultural Hierarchy in America. Cambridge: Harvard University Press.

M cDonald, Ronan. 2007. The Death of the Critic. London: Continuum.

Peterson, Richard A. 1997. The rise and fall of highbrow snobbery as a status marker." Poetics 25(2/3): 75-92.

Peterson, R.A. and Kern, R.M . (1996) "Changing highbrow taste: From snob to omnivore." American Sociological Review 61(5): 900-907.

Purhonen, Semi, Riie Heikkilä, and Irmak Karademir Hazir. 2017. "The grand opening? The transformation of the content of culture sections in European newspapers, 1960-2010." Poetics 62: $29-42$.

Riffe, Daniel, Charles F. Aust, and Stephen R. Lacy. 1993. "The effectiveness of random, consecutive day and constructed week samples in newspaper content analysis." Journalism \& Mass Communication Quarterly 70(1): 133-139.

Schreier, Margrit. 2012. Qualitative Content Analysis. London: Sage.

Shrum, Wesley. 1996. Fringe and Fortune: The role of critics in high and popular art. Princeton, NJ: Princeton University Press.

Shrum, Wesley. 1991. "Critics and publics: Cultural Mediation in Highbrow and Popular Performing Arts." American Journal of Sociology 97 (2): 347-375. 
Smith Maguire, Jennifer, and Julian M atthews. (eds) 2014. The Cultural Intermediaries Reader. London: Sage.

Van Rees, Kees, and Jeroen Vermunt. 1996. "Event history analysis of authors' reputation: Effects of critics' attention on debutants' careers." Poetics 23: 317-333.

Van Venrooij, Alex, and Vaughn Schmutz. 2010. "The evaluation of popular music in the United Stated, Germany and the Netherlands: A comparison of the use of high art and popular aesthetic criteria." Cultural Sociology 4: 395-421.

Verboord, M arc. 2014. "The impact of peer-produced criticism on cultural evaluation: A multilevel analysis of discourse employment in online and offline film reviews." New M edia \& Society 16(6): 921-940.

Verboord, Marc, and Susanne Janssen. 2015. "Arts journalism and its packaging in France, Germany, The Netherlands and The United States, 1955-2005." Journalism Practice 9 (6): 829852.

Verboord, M arc, Giselinde Kuipers, and Susanne Janssen. 2015. "Institutional recognition in the transnational literary field, 1955-2005." Cultural Sociology 9(3): 447-465.

Weibull, Lennart, and Åsa Nilsson. 2010. "Four decades of European newspapers: Structure and content." In M edia, M arkets \& Public Spheres, edited by Jostein Gripsrud and Lennart Weibull, 3970. Bristol: Intellect. 